Document downloaded from:

http://hdl.handle.net/10251/124299

This paper must be cited as:

Sanz, MT.; Caselles, A.; Micó, JC.; Soler Fernández, D. (2018). A stochastic dynamical social model involving a human happiness index. Journal of Computational and Applied Mathematics. 340:231-246. https://doi.org/10.1016/j.cam.2018.02.036

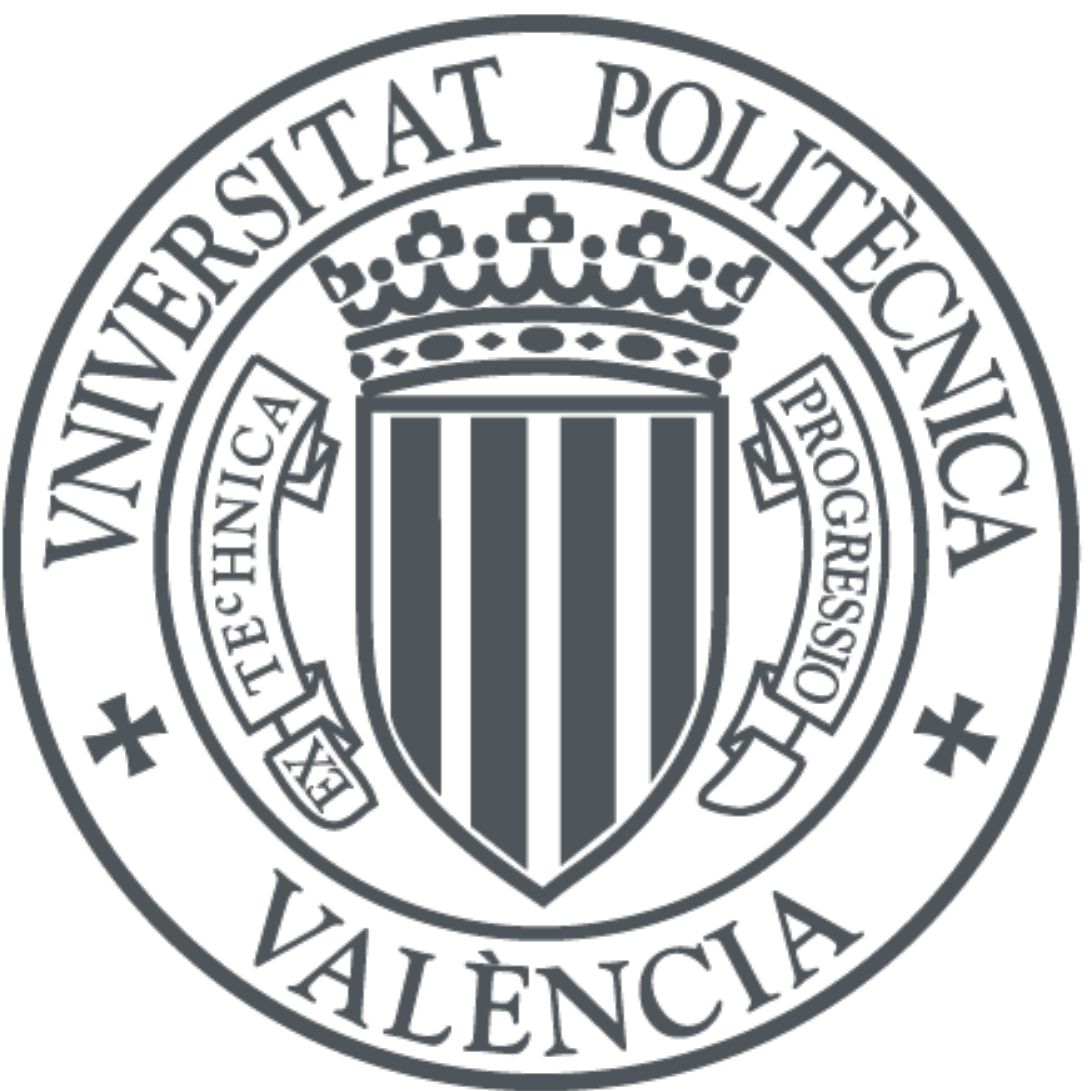

The final publication is available at

http://doi.org/10.1016/j.cam.2018.02.036

Copyright Elsevier

Additional Information 


\title{
A stochastic dynamical social model involving a human happiness index
}

\author{
María T. Sanz ${ }^{\mathrm{a}^{*}}$, Antonio Caselles ${ }^{\mathrm{b}}, \mathrm{J}_{\text {oan C. Micó }}^{\mathrm{c}}$, David Soler ${ }^{\mathrm{c}}$ \\ a Departament de Didàctica de la Matemàtica, Universitat de València, Avda. Tarongers 4, \\ 46022 València, Spain \\ b IASCYS member. Departament de Matemàtica Aplicada, Universitat de València, Dr. Moliner 50, 46100 Burjassot, \\ Spain. \\ c Institut Universitari de Matemàtica Multidisciplinar, Universitat Politècnica de València, Camí de Vera s/n, 46022 \\ València, Spain
}

\begin{abstract}
This paper presents a new human happiness index built through five dimensions: development, freedom, solidarity, justice and peace. These five dimensions are evaluated through quantitative variables obtained from the Human Development Reports, World Data Bank and Eurostat. The new happiness index has been built following the guidelines set by the Human Development Reports of the $U N$ for the construction of quality indices, and it has been compared on a set of 13 EU countries with the Overall Life Satisfaction Index, which is used by the UN. Moreover, the new index has been included in a dynamic mathematical model through the demographic rates to study the evolution of the population. The obtained model has been calibrated for the period 2004-2009 and validated for the period 2010-2015 for the case of Spain. Finally, the model has been used to maximize the happiness index in Spain for the period 2016-2030, with the conclusion that to achieve this purpose, it is necessary to invest in education, research and development.
\end{abstract}

Keywords: Stochastic dynamical model; happiness index; population dynamics; forecasting.

\section{Introduction}

Happiness, as a permanent trait, can be defined as a feeling of satisfaction with life [1], and therefore, most people believe that it is the basis of a meaningful life [2]. For this reason, the intention to measure happiness is increasing. The literature reflects two different ways to measure this concept.

On the one hand, there are authors that try to measure the individual happiness of each person. The International Institute of Management created the Gross National Happiness Index [3], in which the state of a person is measured from 1 to 10. It consists of 7 dimensions: economic, environmental, physical, mental, work, social, and political. The Scale of Life Satisfaction [4] is designed to measure global cognitive judgments of satisfaction with one's life, and it is measured from 5 questions that are answered on a scale ranging from 1 to 7. The Scale of Subjective Happiness [5] asks four questions to measure the happiness, also on a scale from 1 to 7 . There are other authors $[6,7,8]$ who measure the happiness of a person and relate it with economic variables.

On the other hand, there are institutions that try to measure the happiness of a country. The Happy Planet Index (HPI) [9] captures the degree to which long and happy lives are achieved per unit of environmental impact. It is calculated through four parameters, a) life expectancy at birth (the average number of years an infant born in that country is expected to live); b) experienced well-being (the average of all responses from within the population to a question that measures how people's lives are going overall); c) inequality outcomes (a measure of how unequal the distribution of life expectancy and experienced well-being scores are within a particular country);

\footnotetext{
* Corresponding author. Tel.:+34 963983285.

E-mail addresses: m.teresa.sanz@uv.es (M.T. Sanz); antonio.caselles@uv.es (A. Caselles); jmico@mat.upv.es (J.C. Micó); dsoler@mat.upv.es (D. Soler)
} 
and d) ecological footprint (the average amount of land needed, per head of population, to sustain a typical country's consumption patterns). The Gross National Happiness (GNH) [10] is an index based on a subjective questionnaire of 180 questions and that considers 9 dimensions: psychological well-being, use of time, vitality of the community, culture, health, education, environmental diversity, standard of living and government. Finally, the Overall Life Satisfaction Index [11] involves subjective well-being questions about health, wealth, and access to basic education.

However, most of these indicators are based on answers of a sample of population to questionnaires and their results are subject to a number of caveats. Moreover, as Frey [7] says: "the measures are sensitive to the context in which they are asked".

This paper presents a new happiness index for a country, which hereinafter will be called Happiness Index $(H A I N)$. It introduces two substantial improvements with respect to those provided by the literature. On the one hand, this index does not use variables measured through the answers of a sample of population to questionnaires; all the involved concepts are translated through quantitative variables obtained from statistical data bases, that represent the entire population of a country, and can be easily updated since they are collected every year by the respective organisms from real data. On the other hand, it uses and extends the concepts that other indices also measure, by using new quantitative variables such as education quality, migration, and exports and imports of goods and services. Note that most dimensions used in the HPI and $G N H$ are involved in our index, but as quantitative variables. This fact will be clear after the definition of HAIN at the end of Section 2.

Assuming that happiness of people is equivalent to "satisfaction with their life" [1], that the respect to the human dignity in a country is equivalent to the respect to human rights [12], and that when human rights are respected people should be satisfied with their life, HAIN is calculated through the terms studied by Caselles [12], who presented an exhaustive analysis of the literature on this topic and considered that human dignity has development, freedom and equality as immediate subordinate values, and that subordinate values to equality are solidarity, justice and peace. That is because equality justifies so much solidarity as justice and peace, i.e., all subsidiary values of solidarity (non-discrimination, same rights, social help, etc.), justice (protection by law, appeal to courts, right of property, etc.) and peace (prohibition of slavery, servitude, torture and arbitrariness, right to a legal personality, etc.) are indicators of equality. Caselles [12] also showed an exhaustive list of variables inspired in human rights that could be related with these values. A representative selection of these variables have been chosen for the construction of the index presented here. The formulas used to obtain HAIN have been designed following the guidelines stated by the Human Development Reports [11] of the $U N$ for the construction of quality indices.

Note that HAIN will not reflect the environmental average impact, contrarily to the HPI. This is due to the fact that an environmental index already exists [13], which will also be taken into account in the dynamic model that will be proposed in this paper.

The first objective of this article derives from the translation of the values implied in happiness into quantitative variables, that is, to obtain the minimum set of quantitative variables to explain the values development, freedom, solidarity, justice and peace, as well as to obtain a generic formula for HAIN, which allows measuring the happiness of a country/region from the five cited values. The term "generic" is introduced because this formula could be extrapolated to any country, even though in this work the index has been calculated for a selection of 13 countries of the European Union in 2013, because the required data information is not available for all countries in the UNDP reports [11] and Eurostat [14].

The second aim of this paper is to add the obtained index to a stochastic dynamic model through the demographic rates (see Figure 1) and thus being able to forecast by simulation its possible future values as a tendency or as a consequence of determined government policies. Previous works use quality of life variables to compute demographic rates. For instance, Sanz et al. [13] 
created an environmental index that was introduced in the rates of fecundity and mortality, showing how this index affects both rates. Sanz et al. [15] also used the Gender Development Index [11] to calculate the rates of fecundity. More recently, Soler et al. [16] calculated the demographic rates from variables related to health, economy, education and female work. Marques et al. [17] emphasized the importance of migratory flows in the happiness of a country. Literature also relates the migration of a country with commerce, investment or the size of the own country $[18,19]$. Some of these models have been used with the purpose of observing or improving some of the studied variables in a future period. For example, the model by Sanz et al. [15] allowed to study optimal strategies to increase the quality of life or to obtain a demographically stable society for the case of Spain, and the model by Soler et al. [16] sets standards to reduce the rate of unemployment in Spain in 2025.

In agreement with [17], migration is introduced like a variable to calculate the happiness index that appears in this work, and the immigration and emigration rates have been calculated through the happiness index.

\section{(Please Insert Figure 1 about here)}

Finally, we find in the literature some controversy on the relationship between the economy and the happiness of a country. Some authors claim that economy influences happiness [20,21], while others question this influence. For example, Aparicio [22] indicates that consumption may exert an ambiguous or insignificant influence on subjective well-being. Thus, the third objective of this paper is to use the dynamical model presented here to increase the happiness of a country by maximizing $H A I N$, being one of the strategy variables the gross national income per capita, which will allow observing the influence of this variable on the happiness of a country, and therefore, somehow, mediate in the controversy.

The rest of the paper is organized as follows. Section 2 builds the Happiness Index through the five main values mentioned above, shows the country rank for each value on a set of $13 \mathrm{EU}$ countries, and compares the Happiness Index with the Overall-Satisfaction Index from the UNDP Reports [11], in this set of countries in 2013. Section 3 presents and validates a stochastic dynamic model, which includes the Happiness Index as a central variable. Section 4 shows some strategies and scenarios to improve the happiness index in the 2030 horizon. Finally, Section 5 presents conclusions and some suggestions for future research.

\section{The Happiness Index}

As stated above, in this work the happiness of a country is considered as synonymous of "degree of respect to the human dignity" in this country and consequently as the disaggregation of five different dimensions: development, solidarity, justice, peace and freedom. From these five concepts we obtain the quantitative variables that allow us to get closer to its meaning and to quantify it through HAIN. Note that equality is integrated by solidarity, justice and peace [12] as stated above.

The methodology to obtain HAIN is the methodology used in UNDP Reports [11]. In this methodology, minimum and maximum values (limit values) are determined to transform the real variables into variables which values are between 0 and 1 . With this procedure, different variables can be used in the same formula because they have the same dimension.

The minimum and maximum values are obtained by two different ways. On the one hand, the values of the variables obtained from the UNDP Reports are selected from the time series 1996- 
2014. On the other hand, the values of the variables obtained from Eurostat [14] or World Data Bank [23] are chosen from the time series 1989-2015. Note that these extreme values are universal, in the sense that they are fixed in the formulas regardless of the country being studied. If a country exceeds the maximum value, the value of the corresponding transformation variable will be considered equal to 1 , while if a country does not reach the minimum, the value will be considered equal to 0 . The latter does not occur in practice, since most of the minimum values considered are 0 . As an instance, the minimum and maximum values to compute the Gross National Income per Capita (PPP US dollar) are respectively 100 and 75000, stated universally in the technical notes of the UNDP reports [11].

In all cases, to calculate the values of the variables corresponding to the five basic concepts, as well as to HAIN, the geometric mean is used, following the guidelines given by the UNDP reports [24]. In addition, when it has been possible, the variables used have been obtained differentiated by sex, since they provide disaggregation of the index and therefore more detail and information, for example, by introducing them in a demographic model distinguishing sexes, as in this work. Unfortunately, not all the variables could be obtained differentiated by sex in the data bases, for instance, the performance of 15-year-old students in reading, mathematics and science, the international inbound tourists, the pupil-teacher ratio, the mobile phone subscriptions/internet users, at-risk-of-poverty rate, etc. So this paper does not present an index of happiness for women and another one for men, which would be an ideal, although we hope that in the future it will be possible.

\subsection{Development}

The definition considered for development [12] is: "Options of survival and self-fulfilment. It includes: life/health, social progress (education, culture, etc.) and standard of life (economic resources, comforts, etc.)".

It is related with the well-known Human Development Index (HDI) [24], but the HDI is not used in this paper because $H A I N$ is built using many variables differentiated per gender while $H D I$ does not. It exists another $U N$ index, the Gender Development Index (GDI) [24], which measures gender gaps in human development achievements by accounting for disparities between women and men in three basic dimensions: health, knowledge and living standards, using the same component indicators and the same methodology than the HDI. Nevertheless, the GDI is not the variable used here to study the development, but the following other variables related with the GDI that are explained in detail in the UNDP Reports:

$X E B I$ Life expectancy at birth: Number of years a new born infant could expect to live if prevailing patterns of age-specific mortality rates at the time of birth stay the same throughout the infant's life.

$$
\begin{aligned}
\text { xebi } & =\frac{1}{\frac{\text { prpf }}{\left(\frac{x e b f-22.50}{87.50-22.50}\right)}+\frac{\text { prpm }}{\left(\frac{x e b m-17.50}{82.50-17.50}\right)}} \\
\text { prpf } & =\frac{\text { popf }}{\text { popt }}
\end{aligned}
$$




$$
p r p m=\frac{\text { popm }}{\text { popt }}
$$

Where $X E B F$ and $X E B M$ are the female and male life expectancy at birth respectively. $P R P F$ and $P R P M$ are the female and male proportion respectively. $P O P F$ female population, $P O P M$ male population and $P O P T$ total population.

$E D I F$ and EDIM are the Education Indices by gender.

$$
\begin{aligned}
\text { edif }= & \frac{\frac{x y s f-0}{15-0}-\frac{e y s f-0}{18-0}}{2} \\
\text { edim }= & \frac{\frac{x y s m-0}{15-0}-\frac{e y s m-0}{18-0}}{2}
\end{aligned}
$$

Once EDIF and EDIM have been computed, the (global) Education Index EDIN is obtained.

$$
\text { edin }=\frac{1}{\frac{\text { prpf }}{\text { edif }}+\frac{\text { prpm }}{\text { edim }}}
$$

Where XYSF and XYSM are female and male mean of schooling years respectively: Average number of years of education received by people of ages 25 and older, converted from education attainment levels using official durations of each level. EYSF and EYSM are female and male expected years of schooling respectively: Number of years of schooling that a child of school entrance age can expect to receive if prevailing patterns of age-specific enrolment rates persist throughout the child's life.

Note that when the data per gender are not available we consider XYSC (mean of schooling years: Average number of years of education received by people of ages 25 and older, converted from education attainment levels using official durations of each level) instead of XYSF and XYSM, and EYSC (expected years of schooling: Number of years of schooling that a child of school entrance age can expect to receive if prevailing patterns of age-specific enrolment rates persist throughout the child's life) instead of EYSF and EYSM (for more details, see the list of equations in the Appendix).

GNIP Gross National Income per capita (measured in purchasing power parity dollars): Aggregate income of an economy generated by its production and its ownership of production factors minus the incomes paid for the use of production factors owned by the rest of the world, converted to international dollars.

$$
\text { gnip }=\frac{1}{\left(\frac{\log (\text { gnif })-\log (100)}{\log (75000)-\log (100)}\right)}+\frac{\text { prpm }}{\left(\frac{\log (\text { gnim })-\log (100)}{\log (75000)-\log (100)}\right)}
$$

Where GNIF and GNIM are the female and male Gross National Income per capita respectively. 
Note that Health is measured by life expectancy at birth. This variable can embrace the level of Health in a country.

In the case of Education, Quality should be included. This concept is shown in Table 10 of reference [11]. The Education Quality EDLI is given through Eq. (8).

$$
\text { edli }=\sqrt[4]{\frac{\frac{p s t t-0}{100-0} \cdot \text { prms } \frac{\text { pexe-2 }}{10-2}}{\frac{r p t s-7}{25-7}}}
$$

Where:

PSTT Primary school teachers trained to teach: Percentage of primary school teachers that have received the minimum organized teacher training (pre-service or in-service) required for teaching at the primary level.

PRMS Performance of 15-year-old students in reading (PERE), mathematics (PEMA) and science (PESC): Score obtained by testing of skills and knowledge of 15 -year-old students in these subjects essential for participation in society. It is calculated as in reference [11].

$$
\text { prms }=\frac{\left(\frac{\text { pere }-100}{1000-100}\right)+\left(\frac{\text { pema }-100}{1000-100}\right)+\left(\frac{\text { pesc }-100}{1000-100}\right)}{3}
$$

RPTS Pupil-teacher ratio, primary school: Average number of pupils per teacher in primary education in a given school year.

PEXE Public expenditure on education: Currency and capital spending on education, expressed as a percentage of $G D P$.

Finally, the Development Index, DEIN, is calculated with Eq. (10), and the results for the 13 EU countries considered are shown in Table 1.

$$
\text { dein }=\sqrt[4]{x e b i \cdot \text { edin } \cdot \text { gnip } \cdot \text { edli }}
$$

\subsection{Freedom}

The considered definition of freedom [12] is: "Non-restrictions to self-fulfilment. This would be the total freedom that, obviously, in a group must be limited by the dignity of the other members of the group". Eq. (11) presents the quantitative variables selected to obtain the Freedom Index, FRIN,

$$
\text { frin }=\sqrt[6]{\frac{\text { rami }-(-1000)}{1000-(-1000)} \cdot \frac{x n s t-0}{100-0} \cdot \frac{x i t o-0}{100000-0} \cdot \frac{x p s u-0}{100-0} \cdot \frac{\text { exim }-0}{100-0} \cdot \frac{\text { rede }-0}{5-0}}
$$

Where,

RAMI Net migration rate: Ratio of the difference between the number of immigrants and emigrants from a country to the average population, expressed per 1,000 people.

XNST Stock of immigrants: Ratio of the stock of immigrants inside a country, expressed as a percentage of the country's population. The definition of immigrant varies across countries but 
generally includes the stock of foreign born people, the stock of foreign people (according to citizenship) or a combination of the two.

XITO International inbound tourists: Arrivals of non-resident visitors (overnight visitors, tourists, same day visitors and excursionists) at national borders.

$X P S U$ Mobile phone subscriptions/Internet Users: Number of subscriptions for the mobile phone service expressed per 100 people.

EXIM Exports and imports: The sum of exports and imports of goods and services, expressed as a percentage of gross domestic product $(G D P)$. It is a basic indicator of openness to foreign trade and economic integration and indicates the dependence of domestic producers on foreign demand (exports) and of domestic consumers and producers on foreign supply (imports), relative to the country's economic size $(G D P)$.

REDE Research and development expenditure. Current and capital expenditures (both public and private) on creative work undertaken systematically to increase knowledge and the use of knowledge for new applications, expressed as a percentage of GDP. It covers basic research, applied research and experimental development.

All these variables have been obtained from Table 13 of the UNDP [11].

Table 1 shows the values of this index for each one of the 13 studied countries.

Note that FRIN is measured only in terms of opening the country to the outside, unlike other freedom indices such as Human Freedom Index [25], CIRI Human Rights Dada Project [26], Democracy Index [27], or Index of Economic Freedom [28]. This is due to the fact that most of the variables considered in these indices and not in FRIN are considered in other subcomponents of HAIN, and that other ones are not considered because of lack of the corresponding statistical data in accessible data bases. Moreover, those indices have been obtained through inquiries that are not realized every year (for instance: Human Freedom Index is only calculated for 2015 and 2016, CIRI is calculated since 1981 to 2011 and Democracy Index has not information for 2007 and 2009), and consequently there are not time series available of the mentioned indices, which we would need to calibrate and to validate the model presented in this paper.

\subsection{Peace}

According to [12], peace can be defined as "absence of violence, coercion and fear".

The Peace Index, PEIN, is calculated as Eq. (12) reflects and the corresponding values for each country are given in Table 1 .

pein $=1-\sqrt{\frac{\text { raho-0 }}{100000-0} \cdot \frac{\text { crpo-0 }}{100-0}}$

Where,

$C R P O$ Crimes and violence (\%) and $R A H O$ Homicide rate: Number of unlawful deaths purposefully inflicted on a person by another person, expressed per 100,000 people.

Note that the Peace Index differs in the way of being calculated from the rest of the indices previously calculated. It is calculated as 1 minus the "index of conflicts". This last index is the geometric average of the two variables above cited.

\subsection{Solidarity}

Solidarity is considered [12] synonymous of brotherhood, that is, mutual aid. The information to create the Solidarity Index, SOIN, is obtained from EUROSTAT.

The Solidarity Index, SOIN, is calculated as follows: 


$$
\operatorname{soin}=\sqrt[3]{\left(1-\frac{r i p r-0}{100-0}\right) \cdot\left(1-\frac{p l d w-0}{100-0}\right) \cdot\left(1-\frac{\text { madr }-0}{100-0}\right)}
$$

Where:

$R I P R$. At-risk-of-poverty rate. The share of persons with an equivalent disposable income below the risk-of-poverty threshold, which is set at $60 \%$ of the national median equivalent disposable income (after social transfers).

$P L D W$. Share of total population living in a dwelling with a leaking roof, damp walls, floors or foundation, or rot in window frames of floor.

$M A D R$ Material Deprivation rate. The indicator is defined as the percentage of population with an enforced lack of at least three out of nine material deprivation items in the 'economic strain and durables' dimension.

Table 1 shows the values of this index.

Note that: (a) the UNDP reports [11] consider RIPR as a parameter of the Multidimensional Poverty index and not of the Human Development; (b) RIPR data are obtained from Eurostat [14], where the definition of income includes all sources (even donations); (c) in [12] the risk of poverty is considered as a component of the solidarity index.

\subsection{Justice}

Finally, justice is considered [12] as the set of "mechanisms of prevention, protection and compensation for individuals or groups face to possible damages or benefits".

In this case, descriptors are not in the UNDP Reports. For this reason, the information is obtained from statistical data bases. In EUROSTAT the only available data about this matter are: Police Officers (POOF) and Professional Judges (PRJU) per capita. Taking into account this drawback, the Justice Index, JUIN, is calculated through Eq. (14). Table 1 shows the results.

juin $=\sqrt{\left(1-\frac{\frac{p o o f}{p o p t}-0}{1-0}\right) \cdot\left(1-\frac{\frac{p r j u}{p o p t}-0}{1-0}\right)}$

Once the five required indices have been calculated, the Happiness Index is obtained through Eq. (15).

$$
\text { hain }=\sqrt[5]{\text { dein } \cdot \text { frin } \cdot \text { juin } \cdot \text { pein } \cdot \text { soin }}
$$

Note that all five dimensions (and also their respective sub-dimensions) are equally weighted following the present criteria of the UNDP Reports [11].

The obtained values for this index in each one of the 13 studied countries appear in Table 1. We have decided to compare HAIN with an existing index that tries to measure the happiness of a country in a similar sense. We have chosen the Overall Life Satisfaction Index because it is provided by the UNDP in its report [11] (see Table 1 for the comparison). We observe that both indices present similar values in this set of countries, with a coefficient of determination of 0.609 .

(Please Insert Table 1 about here) 
Given that Spain is the country that will be used for the validation of the model presented in the next section, as well as for the forecast, Fig. 2 presents the trend of HAIN in the period 2003-2015 in Spain.

\section{(Please Insert Figure 2 about here)}

Remark that this new happiness index for a country has two substantial improvements regarding the other published indices. On the one hand, this index extends the concepts that other indices measure, as Table 2 shows. On the other hand, the concepts that HAIN considers have been represented by numerical variables, which have been obtained from data bases. This second progress allows us to introduce the index in a dynamic model (presented in Section 3) that permits to perform simulations and to make forecasts. Environment is not considered in HAIN because a specific environmental index (EQUI) is used in our model. Moreover, concepts such as psychological well-being, use of time or vitality of the community cannot be considered in HAIN because they have not a specific corresponding variable in data bases. Finally, culture and government are not included directly in HAIN.

\section{(Please Insert Table 2 about here)}

\section{The demographic model}

The starting point of the demographic model is the model presented by Micó et al. [29] without age structure, where all variables depend on time $t \in\left[t_{0}, \infty[, i=1\right.$ refers to female and $i=2$ refers to male:

$$
\frac{d p o p l_{i}(t)}{d t}=r f e r_{i}(t) \cdot \operatorname{popl}_{1}(t)-r d e f_{i}(t) \cdot \operatorname{popl}_{i}(t)+\left(\operatorname{rinm}_{i}(t)-\operatorname{remm}_{i}(t)\right) \cdot \operatorname{popl}_{i}(t)
$$

Where $P O P L_{i}$ is the total population per sex, $R F E R_{i}$ is the birth rate per sex, $R D E F_{i}$ is the death rate per sex, and $R I N M_{i}$ and $R E M M_{i}$ are the immigration and emigration rate, respectively.

Previous works have demonstrated that the demographic rates depend on the well-being indices of the UN [15,30] and on the environmental quality index [13].

The second aim of this paper is to introduce the Happiness Index in the demographic rates (of birth, death, emigration and immigration). Figs. 3 and 4 show the Forrester Diagrams [31] of the Happiness Index with the demographic link and of the demographic model with the welfare variables link.

\section{(Please Insert Figure 3 and 4 about here)}

The Forrester diagrams show that the rates depend on the indices EQUI and HAIN:

$$
\begin{aligned}
& \frac{d p o p l_{i}(t)}{d t}=r f e r_{i}(\text { equi, hain }) \cdot \operatorname{popl}_{2}(t)-r d e f_{i}(\text { equi, hain }) \cdot \operatorname{popl}_{i}(t)+\left(\operatorname{rinm}_{i}(\text { equi, hain })-\right. \\
& \left.\operatorname{remm}_{i}(\text { equi, hain })\right) \cdot \operatorname{popl}_{i}(t)
\end{aligned}
$$

Where EQUI is the Environmental Quality Index proposed in [13]. 
Note that all the variables used in the model are defined in Table A.1, given in the Appendix, and the complete equations of the model are also given in the Appendix.

\subsection{Demographic Rates}

The mathematical structures considered to formulate the demographic rates (of fertility, mortality, emigration and immigration) are described as logistic functions of the two indices HAIN and EQUI as follows:

$$
a_{0 i}+\frac{b_{0 i}}{1+\operatorname{Exp}\left[\left(-b_{1 i}+x\right) / b_{2 i}\right]}
$$

Where,

$$
x=\sqrt{\text { hain } \cdot(1-e q u i)}
$$

And, $i=1$ refers to female and $i=2$ refers to male.

Note that $x$ is not differentiated by sex because neither HAIN nor EQUI [13] are differentiated by sex. However, the parameters of Eq. 18 have been differentiated by sex due to the demographic rates also have.

In $[15,30]$ a combination of cosines is chosen to fit the oscillation observed in historical data about demographic rates. However, in [16] the logistic function is considered as producing the best approximation. This last is the one used here.

In [13] the birth and death rates are calculated by multiplying the well-being indices $H D I, G D I$ and GEM, and dividing by EQUI. This is due to the fact that the four indices take values between 0 and 1 but the values close to 1 for the first three mean a quality improvement in the studied country, while the values close to 0 for EQUI represent a better situation with respect to the global warming. The change with respect to this situation that Eq. (19) represents is remarkable. On the one hand, the well-being indices defined by the UN disappear as mentioned above, substituted by $H A I N$. On the other hand, 1-EQUI is a value that has the same positive sense than the well-being indices, being thus justified its introduction in a multiplicative way. Finally, the square root, that represents the geometric mean of both values, allows smoothing its trends. Note that $x$ could be considered as a Global Country Excellence Index, since it has been calculated according to the UNDP guidelines, and involves dimensions such as: environment, economy, education, health, labour, justice, poverty, peace, knowledge, living standards, education quality, freedom and development.

The specific functions of the demographic rates have been found by calibrating the logistic function structure (Eq. 18 and 19) with the finder and fitter tool Regint [32,33]. Regint provides the best adjustment of the function to real data maximizing $\mathrm{R}^{2}$. Next, residuals are checked for randomness and normality through the Kolmogorov-Smirnov test. It is worth noting an improvement in the adjustment of the birth and death rates with respect to existing models $[13,15,16,30]$, since the corresponding determination coefficients increase.

\subsection{Deterministic and Stochastic Validation}

The model has been validated for the case of Spain. The historical data used in this article to fit the model have been obtained from Eurostat and World Data Bank in the 2003-2015 period.

A calibration of the model is performed before its validation. To do this, each one of the input variables used in the construction of HAIN must be fitted with respect to time through the Regint 
software. Note that not all these input variables have a clear time trend; in this case the real data are used instead of the fitted time function.

The calibration has been carried out by writing the model as a set of finite difference equations, and its solutions have been calculated with the Euler approach. This approach is used following the works by Djidjeli et al. [34] and Letellier et al. [35].

Both calibration and validation have been performed in two ways: from the deterministic formulation of the model and from the stochastic formulation. Calibration is carried out in the period 2004-2009 and validation in the period 2010-2015. The software tool used for the model validation is SIGEM [33].

For the deterministic case, calibration can be considered successful due to three facts: the graphic overlapping of the historical data and the calculated data is satisfactory (see Fig. 5); the determination coefficients $R^{2}$ are very high; and the maximum relative error does not exceed 5\%. Validation can also be considered satisfactory for the same reasons (see Fig. 6), but it should be noted that the adjustment is better for men than for women, and that the real values are always below the values predicted by the model, both for women and men. At least this last result may be due to the fact that the first years of this period correspond to the worst years of the economic crisis present in Spain, which supposed an increase in the emigration of the country [14, 23].

\section{(Please insert Figure 5 about here) \\ (Please insert Figure 6 about here)}

For the stochastic formulation of the model, both calibration and validation can be considered successful due to two facts: all results have a normal distribution (this is checked with SIGEM by using a $\chi^{2}$ test), and all real data points are within a $99 \%$ confidence interval for every result (see Figs. 7 and 8).

\section{(Please insert Figure 7 about here) \\ (Please insert Figure 8 about here)}

\section{Forecasts}

As stated in Section 1, the third objective of this paper is to determine by simulation how to increase the happiness of a country in a future period taking into account that demography influences $H A I N$ and EQUI and vice-versa. For this purpose, tentative strategies and scenarios are designed, and its simulation will allow evaluating under what conditions the objective could be fulfilled.

Thus, the different possible hypotheses for future events and actions will be translated into values of the input variables. To this aim, these variables are classified into control variables (those on which specialized organisms can perform actions) (see Table 3), and scenario variables (those that cannot be controlled) (see Table 4).

In order to test the model applicability, we try to solve the tentative problem about if it is better at long term to improve Income or to improve Education, Research and Development and Security. If our results coincide with those of other authors the model would demonstrate its utility. Obviously, many other problems could also be studied with the model, for instance, to try to determine if it is better for long term happiness to improve development of to improve equality.

We design six tentative strategies with those variables that seem controllable:

- Strategy 1: Increasing public expenditure in Education (EYSC, PEXE, RPTS, XYSC), Research and Development (REDE), Income (GNIP) and Security (POOF, PRJU) 
- Strategy 2: Reducing public expenditure in Income and increasing it in Education, Research and Development and Security.

- Strategy 3: Keeping the trend in Income and increasing in Education, Research and Development, and Security.

- Strategies 4, 5 and 6: Keeping the trend in Education, Research and Development, and Security, and increasing, reducing and keeping the trend in Income, respectively.

Also three tentative scenarios have been supposed: Expansive (1), Recessive (2) and Trend (3), with the remaining variables. See Tables 3 and 4 where increase means moving $2 \%$ above tendency and decrease means moving $2 \%$ below tendency.

\section{(Please insert Table 3 about here)}

(Please insert Table 4 about here)

The second step is to define the target variable $\operatorname{HAIN}_{i j}{ }^{k}$, where $i$ describes the strategies, $i \in$ $\{1, \ldots, 6\}, j$ describes the scenarios, $j \in\{1,2,3\}$, and $k$ describes the years under study, $k \in$ $\{2016, \ldots, 2030\}$.

The variable to be optimized is given in Eq. (20), where $p_{j}$ is the probability that experts assign to scenario $j$. In this case, probability $1 / 3$ is assumed for all $j$.

$x h a i_{i}^{k}=\sum_{j=1}^{3} H A I N_{i j}^{k} \cdot p_{j}$

The calculations have been performed with Mathematica 11 [36] and with the simulator generated by SIGEM. Table 5 shows that Strategy 1 maximizes the value of the target variable, i.e. the government would invest in Education, Research and Development. Remark that the difference between the results with Strategy 2 is in the thousandth position, so it could be concluded that an increase (Strategy 1) or a decrease (Strategy 2) in the Gross National Product per capita does not produce a significant variation in happiness for the case of Spain. This coincides with the conclusions given by Aparicio [22], already mentioned in Section 1.

\section{(Please insert Table 5 about here)}

Within Strategy 1, Scenario 1 maximizes variable $H A I N_{l j}{ }^{k}$ (see Table 6).

\section{(Please insert Table 6 about here)}

In addition, more information can be found from this situation. For instance, the decreasing evolution of emigration and immigration per gender in the 2016-2030 period (see Figs. 9 and 10). Note that Marques et al. [17] set up the importance of migration in happiness, concluding that 19 countries between the studied ones have more emigrants than immigrants and are proclaimed as happy in opinion polls, while 23 countries having more immigrants than emigrants self-proclaim unhappy. Our results show that both immigration and emigration descend and the migratory balance is negative (more emigrants) in the simulated period. Consequently, Spain would be like these 19 countries, as Table 6 shows, because HAIN maintains a high level, in spite of decreasing very slightly. 
(Please insert Figure 10 about here)

\section{Conclusions}

This paper presents the constructive process of a new index that measures the happiness of a country. This index extends the concepts that other indices measure, considering the concepts involved in the five dimensions of the index: development, justice, peace, freedom and solidarity. Moreover, it does not use subjective variables measured through questionnaires answered by a sample of population; all the involved concepts are evaluated through quantitative variables obtained from statistical data bases representing the entire population of a country.

Its formulation has been carried out following the Human Development Reports in which wellbeing indices are presented. It has been calculated for the $13 \mathrm{EU}$ countries of which the required data was available, and it has also been compared with the UN Overall Life Satisfaction Index for this set of countries, obtaining a good correlation between both indices.

In addition, this index has been introduced in a demographic model per sexes through demographic rates, namely, birth, mortality, immigration and emigration rates. The mathematical structures of the demographic rates are logistic functions with a specific independent variable, the geometric mean between the new happiness index and a known environmental index. This independent variable could be considered as a global country excellence index, since it covers the main related dimensions.

An improvement in the adjustment of the birth and death rates with respect to existing demographic models must be emphasized, since the determination coefficients increase. The model has been calibrated for the Spanish population per gender in the 2004-2009 period (female $\mathrm{R}^{2}=0.993712$, male $\mathrm{R}^{2}=0.98863$ ) and then validated for the same country in the 2010-2015 period (female $\mathrm{R}^{2}=0.734101$, male $\mathrm{R}^{2}=0.990397$ ), in both the stochastic and deterministic formulations of the model.

Finally, the model has been used to try to carry out future actions to increase the value of the new happiness index in the 2016-2030 period. Six tentative strategies and three scenarios have been designed, and its simulation shows that an increase in this index can be obtained by investing in Education, Research and Development and Security. It is worth noting that income, measured through Gross National Product per capita, does not cause significant variations in the index values. In this optimal situation, the observed decreasing trend of emigration and immigration for the same period is also remarkable.

For future research, we have two objectives. On the one hand, and depending on future available data, we would like to calculate this happiness index for the largest possible number of countries in the world, to compare them and to draw possible conclusions (for example, the relationship between happiness and geographical region, climate, religion, race, etc.), and when necessary, to fine tune the index. On the other hand, we hope to widen, refine and validate the dynamic model presented here for more countries, to include inside it more social and economic variables, in order to use it to find more refined suitable strategies for solving specific governance problems in these countries. 


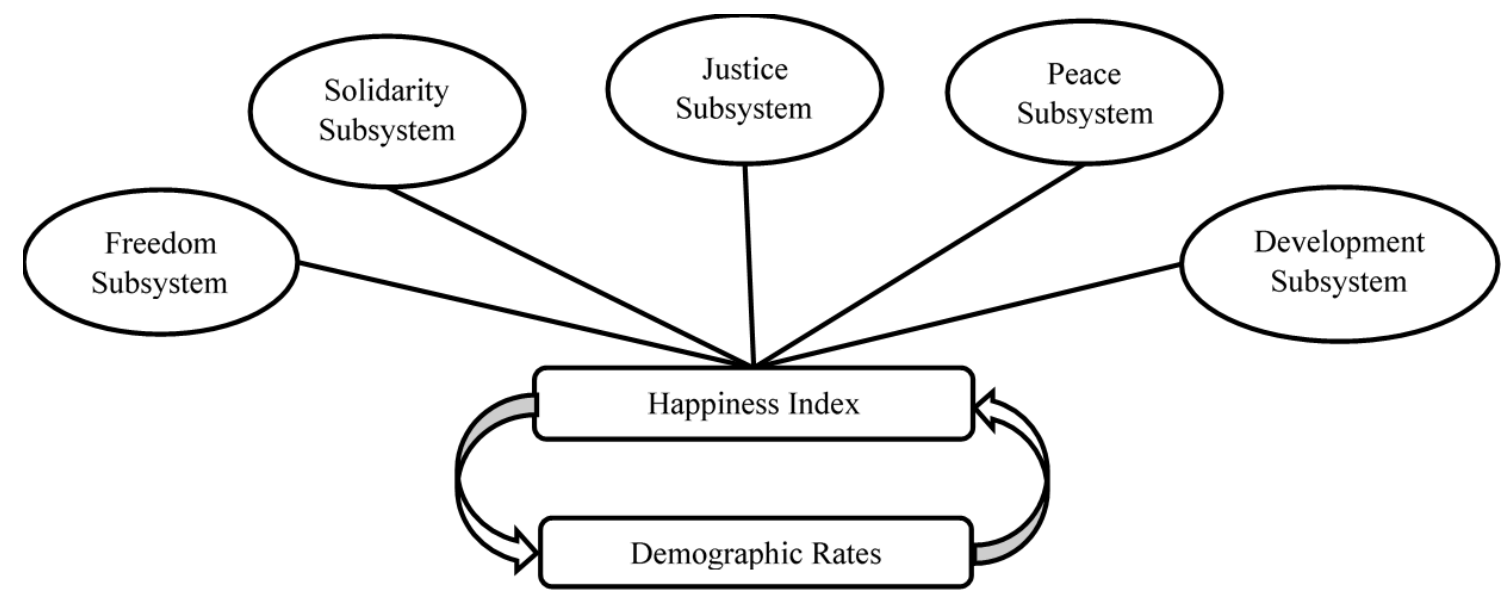

Fig. 1. Causal diagram of the Happiness Index.

\section{Table 1}

The Happiness Index, its main components and the Overall-Satisfaction Index per country. The numbers in bold indicate the maximum and minimum values of each column. Degree of fitting between the Happiness Index and the Overall-Satisfaction Index: $\mathrm{R}^{2}=0.609324$.

\begin{tabular}{lccccccc} 
Country & $\begin{array}{l}\text { Development } \\
\text { Index }\end{array}$ & $\begin{array}{l}\text { Freedom } \\
\text { Index }\end{array}$ & $\begin{array}{l}\text { Peace } \\
\text { Index }\end{array}$ & $\begin{array}{l}\text { Solidarity } \\
\text { Index }\end{array}$ & $\begin{array}{l}\text { Justice } \\
\text { Index }\end{array}$ & $\begin{array}{l}\text { Happiness } \\
\text { Index }\end{array}$ & $\begin{array}{l}\text { Overall- } \\
\text { Satisfaction Index }\end{array}$ \\
\hline Austria & 0.881 & $\mathbf{0 . 4 5 5}$ & 0.837 & 0.877 & 0.998 & 0.736 & 0.74 \\
Croatia & $\mathbf{0 . 7 8 4}$ & 0.205 & 0.899 & 0.771 & $\mathbf{0 . 9 9 7}$ & 0.577 & 0.6 \\
Cyprus & 0.851 & 0.373 & $\mathbf{0 . 6 8 6}$ & 0.72 & $\mathbf{0 . 9 9 7}$ & 0.629 & 0.62 \\
Czech & 0.791 & 0.359 & 0.834 & 0.884 & 0.998 & 0.676 & 0.63 \\
France & 0.841 & 0.321 & 0.87 & 0.872 & 0.999 & 0.672 & 0.66 \\
Iceland & $\mathbf{0 . 9 4 7}$ & 0.326 & $\mathbf{0 . 9 3 5}$ & 0.886 & 0.999 & 0.711 & $\mathbf{0 . 7 6}$ \\
Latvia & 0.827 & 0.288 & 0.728 & $\mathbf{0 . 7 0 3}$ & 0.998 & 0.591 & 0.51 \\
Lithuania & 0.838 & 0.352 & 0.916 & 0.757 & $\mathbf{1}$ & 0.673 & 0.58 \\
Portugal & 0.845 & $\mathbf{0 . 1 8}$ & 0.865 & 0.744 & 0.998 & $\mathbf{0 . 5 5 9}$ & $\mathbf{0 . 5}$ \\
Slovenia & 0.837 & 0.243 & 0.901 & 0.803 & 0.998 & 0.619 & 0.61 \\
Spain & 0.861 & 0.278 & 0.878 & $\mathbf{0 . 9 1 5}$ & 0.998 & 0.719 & 0.63 \\
Sweden & 0.959 & 0.412 & 0.892 & 0.91 & 0.999 & $\mathbf{0 . 7 5 2}$ & $\mathbf{0 . 7 6}$ \\
U.K. & 0.848 & 0.192 & 0.930 & 0.836 & $\mathbf{1}$ & 0.596 & 0.69 \\
\hline
\end{tabular}




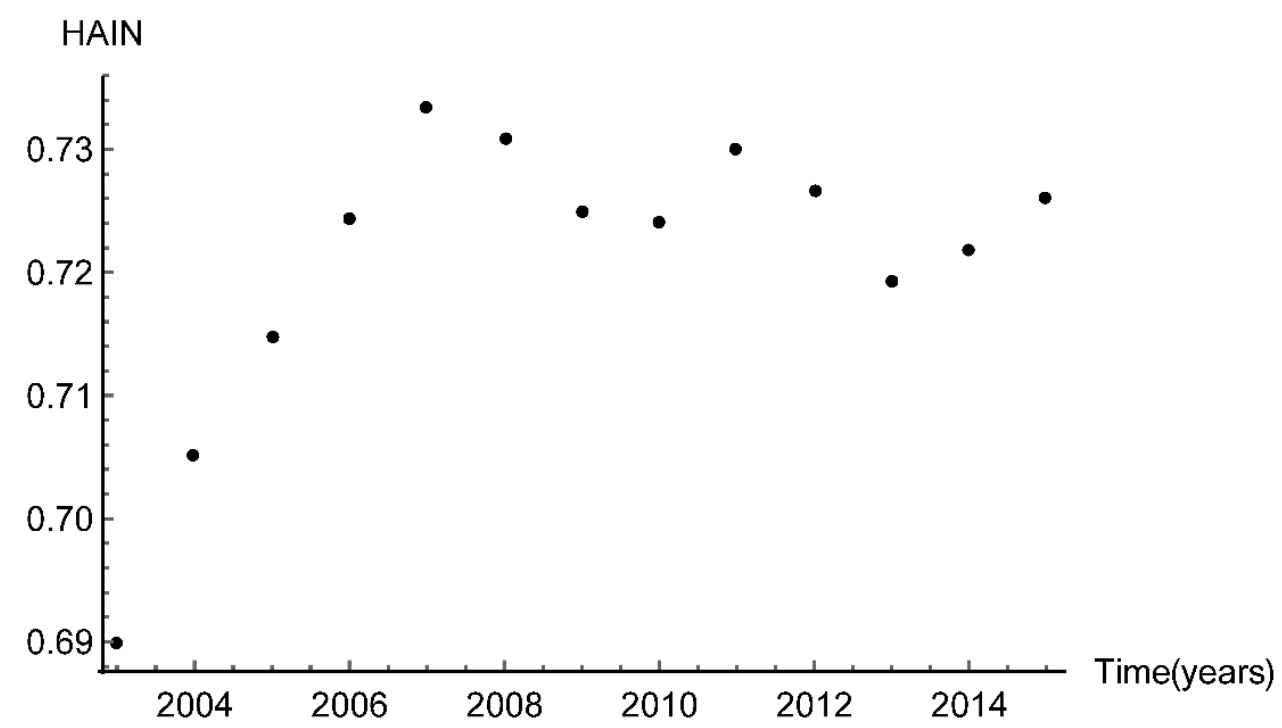

Fig. 2. HAIN values for Spain in the 2003-2015 period.

Table 2

Comparison between HAIN and other indices. An X means that the corresponding dimension or subdimension is considered in the corresponding index.

\begin{tabular}{llcccc}
\hline Dimension & Sub-dimension & HAIN & HPI & GNH & $\begin{array}{c}\text { Overall Life } \\
\text { Satisfaction Index }\end{array}$ \\
\hline Development & Health & $\mathrm{x}$ & $\mathrm{x}$ & $\mathrm{x}$ & $\mathrm{x}$ \\
& Education & $\mathrm{x}$ & & $\mathrm{x}$ & $\mathrm{x}$ \\
& Income & $\mathrm{x}$ & & & \\
Freedom & Investment & $\mathrm{x}$ & & & \\
& Mobility & $\mathrm{x}$ & & & \\
& Research & $\mathrm{x}$ & & & \\
Peace & Communication & $\mathrm{x}$ & & & \\
& Violence & $\mathrm{x}$ & & & \\
Solidarity & Homicide & $\mathrm{x}$ & & & \\
& Poverty & $\mathrm{x}$ & & & \\
Justice & Living Standards & $\mathrm{x}$ & $\mathrm{x}$ & $\mathrm{x}$ & \\
Environment & & $\mathrm{x}$ & & & \\
Use of time & & & $\mathrm{x}$ & $\mathrm{x}$ & \\
Vitality & & & & $\mathrm{x}$ & \\
Culture & & & & $\mathrm{x}$ & \\
Government & & & & $\mathrm{x}$ & \\
\hline
\end{tabular}




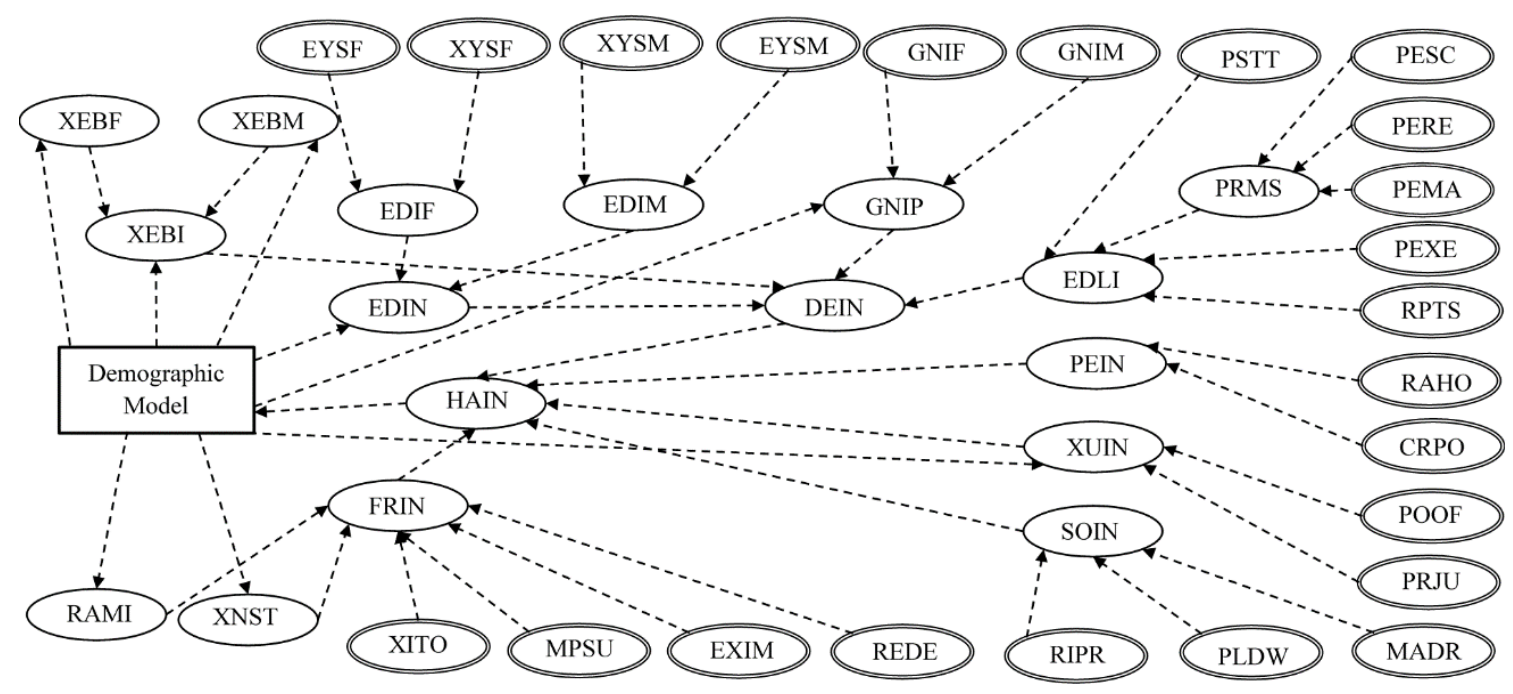

Fig. 3. Causal Diagram of the Happiness Index with the demographic link.

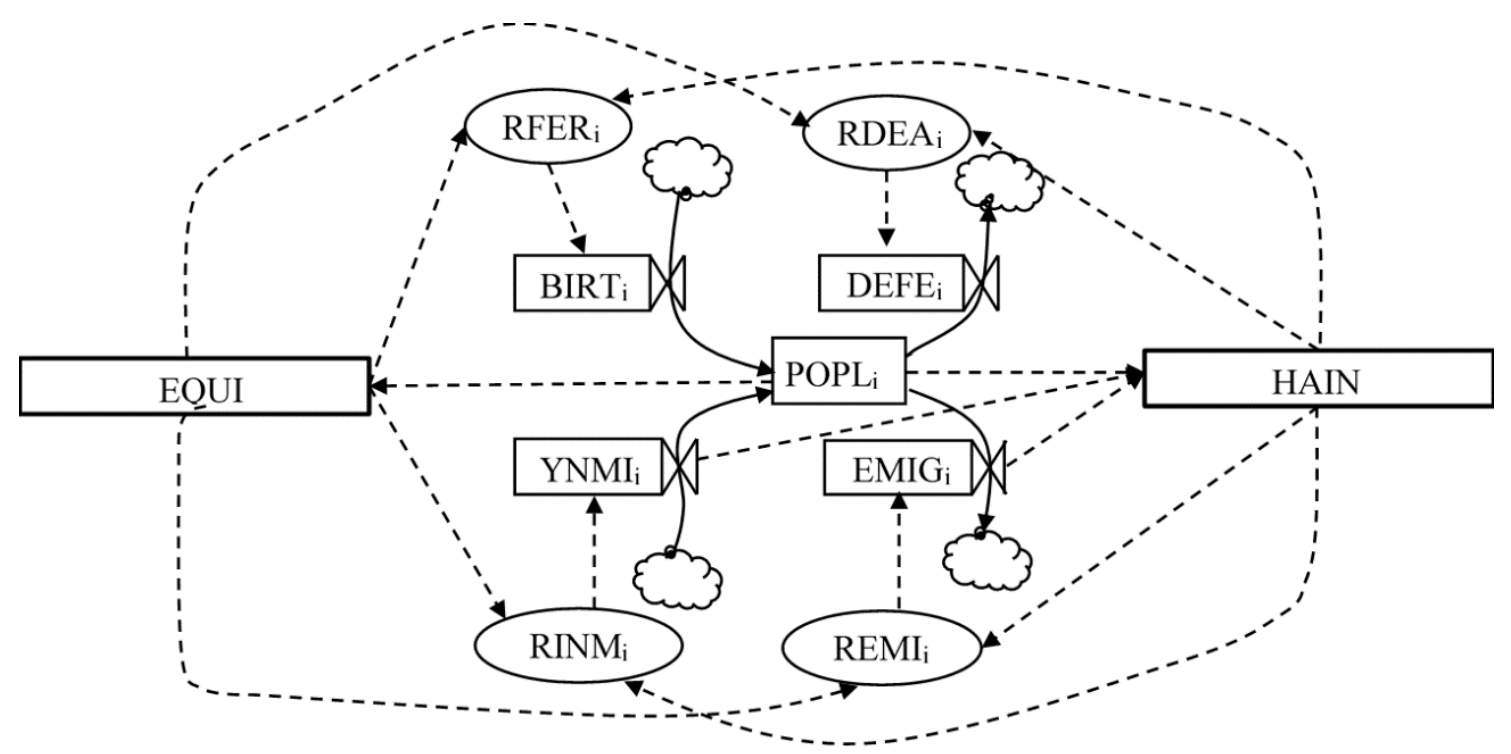

Fig. 4. Forrester Diagram of the demographic model with the welfare variables link. 

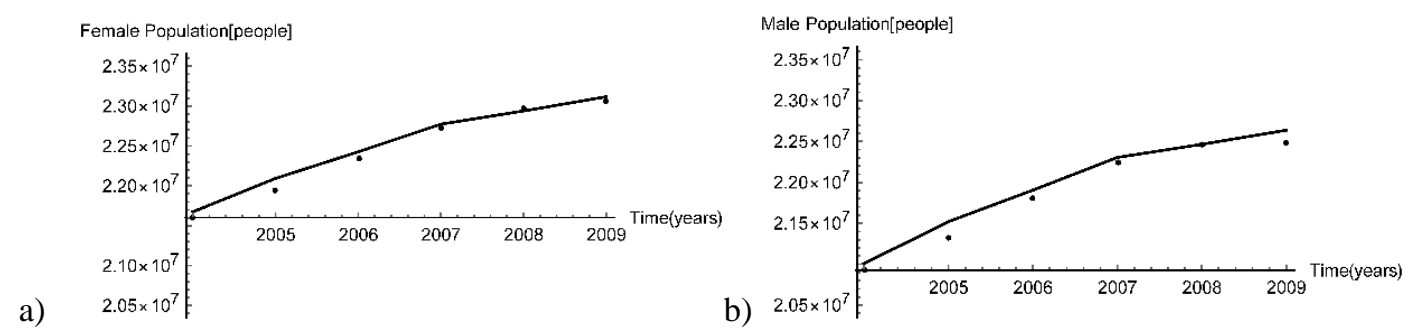

Fig. 5. Deterministic calibration for population: a) female $\left(R^{2}=0.993712\right)$, b) male $\left(R^{2}=0.98863\right)$, in Spain in the 20042009 period. Real data: dots; Simulated data: lines.
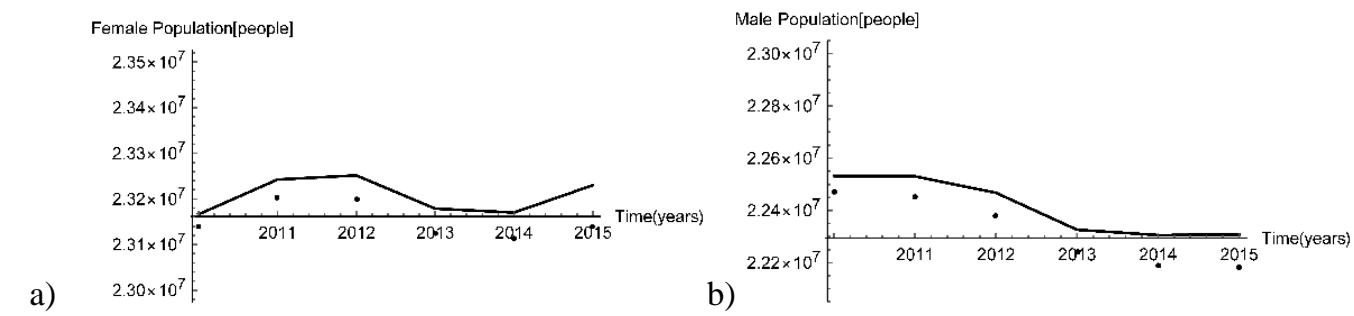

Fig. 6. Deterministic validation for population: a) female $\left(R^{2}=0.734101\right)$; b) male $\left(R^{2}=0.990397\right)$, in Spain in the 2010-2015 period. Real data: dots; Simulated data: lines.
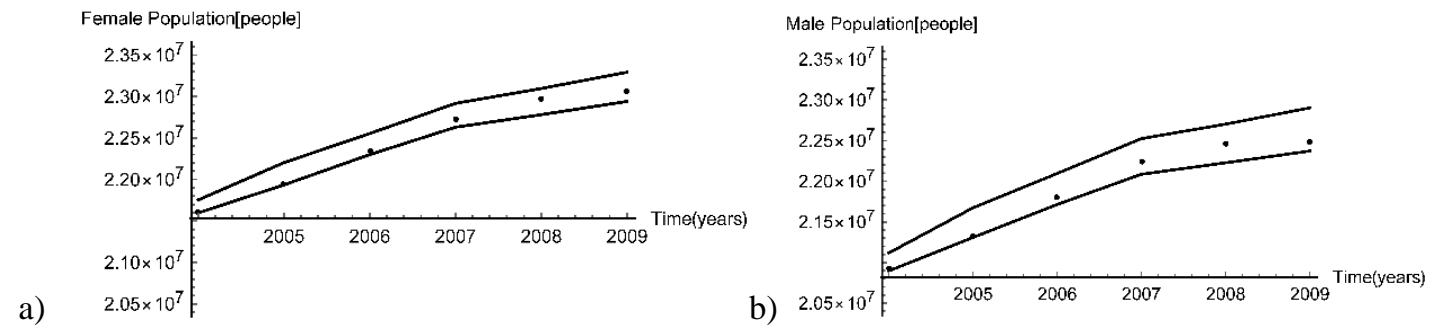

Fig. 7. Stochastic calibration for population: a) female, b) male, in Spain in the 2004-2009 period. Real data: dots. Simulated data (99\% confidence intervals): lines.

a)

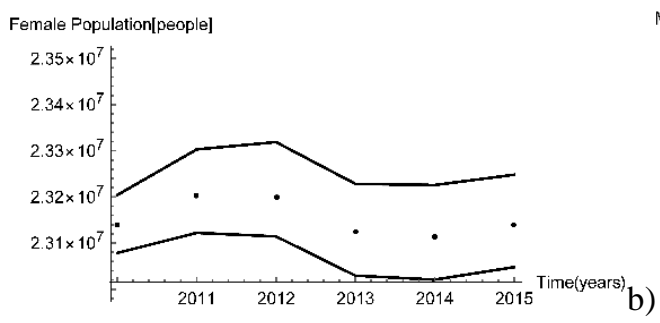

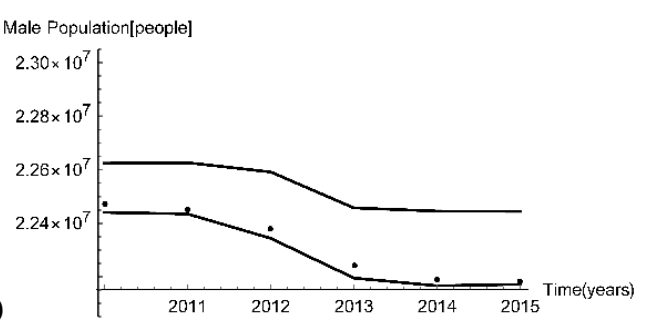

Fig. 8. Stochastic validation for population: a) female, b) male, in Spain in the 2010-2015 period. Real data: dots. Simulated data (99\% confidence intervals): lines. 
Table 3

Definition of strategies. $\uparrow$ increase, $\downarrow$ decrease and $\approx$ keep the tendency.

\begin{tabular}{lcccccc}
\hline Variable & Strategy 1 & Strategy 2 & Strategy 3 & Strategy 4 & Strategy 5 & Strategy 6 \\
\hline EYSC & $\uparrow$ & $\uparrow$ & $\uparrow$ & $\approx$ & $\approx$ & $\approx$ \\
GNIP & $\uparrow$ & $\downarrow$ & $\approx$ & $\uparrow$ & $\downarrow$ & $\approx$ \\
PEXE & $\uparrow$ & $\uparrow$ & $\uparrow$ & $\approx$ & $\approx$ & $\approx$ \\
POOF & $\uparrow$ & $\uparrow$ & $\uparrow$ & $\approx$ & $\approx$ & $\approx$ \\
PRJU & $\uparrow$ & $\uparrow$ & $\uparrow$ & $\approx$ & $\approx$ & $\approx$ \\
REDE & $\uparrow$ & $\uparrow$ & $\uparrow$ & $\approx$ & $\approx$ & $\approx$ \\
RPTS & $\uparrow$ & $\uparrow$ & $\uparrow$ & $\approx$ & $\approx$ & $\approx$ \\
XYSC & $\uparrow$ & $\uparrow$ & $\uparrow$ & $\approx$ & $\approx$ & $\approx$ \\
\hline
\end{tabular}

\section{Table 4}

Definition of scenarios. $\uparrow$ increase, $\downarrow$ decrease and $\approx$ keep the tendency.

\begin{tabular}{lccc}
\hline Variable & Scenario 1 & Scenario 2 & Scenario 3 \\
\hline CRPO & $\downarrow$ & $\downarrow$ & $\approx$ \\
EXIM & $\uparrow$ & $\approx$ & $\approx$ \\
$P E M A$ & $\uparrow$ & $\approx$ & $\approx$ \\
$P E R E$ & $\uparrow$ & $\approx$ & $\approx$ \\
$P E S C$ & $\uparrow$ & $\approx$ & $\approx$ \\
$P L D W$ & $\downarrow$ & $\downarrow$ & $\approx$ \\
$P R P O$ & $\downarrow$ & $\downarrow$ & $\approx$ \\
$R A H O$ & $\downarrow$ & $\downarrow$ & $\approx$ \\
RIPR & $\downarrow$ & $\downarrow$ & $\approx$ \\
$X A D R$ & $\downarrow$ & $\downarrow$ & $\approx$ \\
$X I T O$ & $\uparrow$ & $\approx$ & $\approx$ \\
$X P S U$ & $\uparrow$ & $\approx$ & $\approx$ \\
\hline
\end{tabular}


Table 5

Evaluation of strategies. Values $x h a i_{i}^{k}$ for Spain in the 2016-2030 period.

\begin{tabular}{lllllll}
\hline Year & Strategy 1 & Strategy 2 & Strategy 3 & Strategy 4 & Strategy 5 & Strategy 6 \\
\hline 2016 & 0.73087 & 0.73025 & 0.73057 & 0.72805 & 0.72743 & 0.72829 \\
2017 & 0.73255 & 0.73172 & 0.73198 & 0.72993 & 0.72943 & 0.73015 \\
2018 & 0.72441 & 0.72411 & 0.72434 & 0.72253 & 0.72208 & 0.72269 \\
2019 & 0.72175 & 0.72135 & 0.72159 & 0.71968 & 0.71921 & 0.71984 \\
2020 & 0.72226 & 0.72173 & 0.72198 & 0.72000 & 0.71952 & 0.72018 \\
2021 & 0.72205 & 0.72143 & 0.72167 & 0.71972 & 0.71924 & 0.71989 \\
2022 & 0.71552 & 0.71540 & 0.71564 & 0.71372 & 0.71325 & 0.71387 \\
2023 & 0.71402 & 0.71368 & 0.71392 & 0.71201 & 0.71155 & 0.71216 \\
2024 & 0.71460 & 0.71375 & 0.71399 & 0.71209 & 0.71162 & 0.71223 \\
2025 & 0.71380 & 0.71351 & 0.71375 & 0.71183 & 0.71136 & 0.71197 \\
2026 & 0.71243 & 0.71221 & 0.71245 & 0.71054 & 0.71008 & 0.71067 \\
2027 & 0.71088 & 0.71046 & 0.71070 & 0.70882 & 0.70837 & 0.70894 \\
2028 & 0.71066 & 0.71043 & 0.71067 & 0.70877 & 0.70831 & 0.70888 \\
2029 & 0.70992 & 0.70939 & 0.70963 & 0.70774 & 0.70728 & 0.70784 \\
2030 & 0.70903 & 0.70809 & 0.70832 & 0.70645 & 0.70600 & 0.70655 \\
\hline
\end{tabular}

Table 6

Evaluation of scenarios in Strategy 1. Variables $H_{A I N_{l j}}{ }^{k}$ in Spain in the 2016-2030 period.

\begin{tabular}{llll}
\hline Year & Scenario 1 & Scenario 2 & Scenario 3 \\
\hline 2016 & 0.73416 & 0.73004 & 0.72841 \\
2017 & 0.73593 & 0.73153 & 0.73019 \\
2018 & 0.72649 & 0.72392 & 0.72281 \\
2019 & 0.72392 & 0.72133 & 0.71997 \\
2020 & 0.72521 & 0.72125 & 0.72031 \\
2021 & 0.72501 & 0.72109 & 0.72003 \\
2022 & 0.71814 & 0.71439 & 0.71402 \\
2023 & 0.71622 & 0.71352 & 0.71232 \\
2024 & 0.71703 & 0.71433 & 0.71242 \\
2025 & 0.71628 & 0.71292 & 0.71218 \\
2026 & 0.71481 & 0.71155 & 0.71091 \\
2027 & 0.71326 & 0.71017 & 0.70919 \\
2028 & 0.71291 & 0.70990 & 0.70915 \\
2029 & 0.71216 & 0.70946 & 0.70813 \\
2030 & 0.71154 & 0.70867 & 0.70686 \\
\hline
\end{tabular}




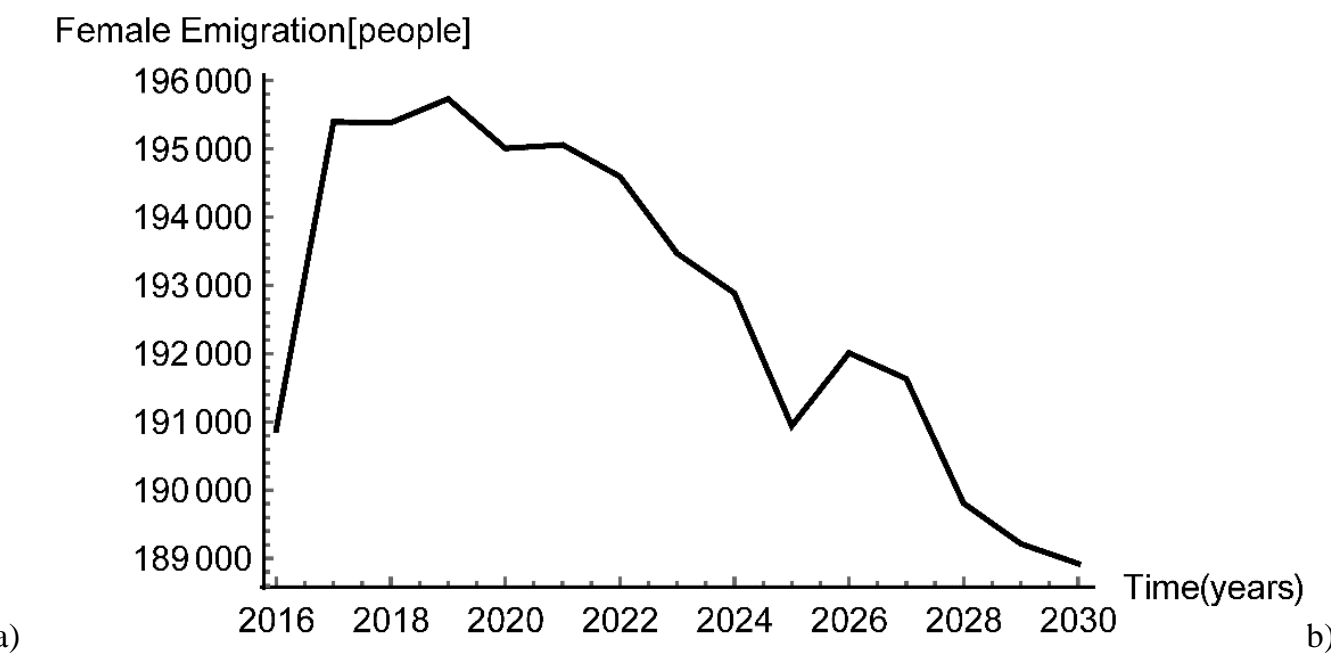

Male Emigration[people]

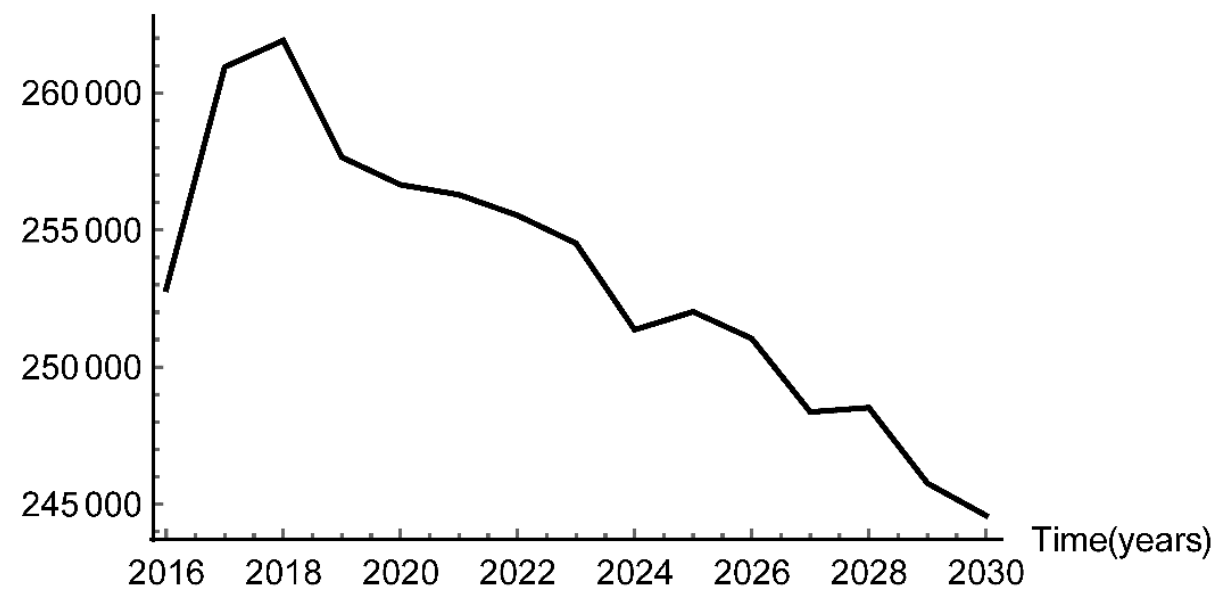

Fig. 9. Extrapolation of Emigration: a) female, b) male, in Spain in the 2016-2030 period, for Strategy 1 and Scenario 1 . 


\section{Female Immigration[people]}

a)

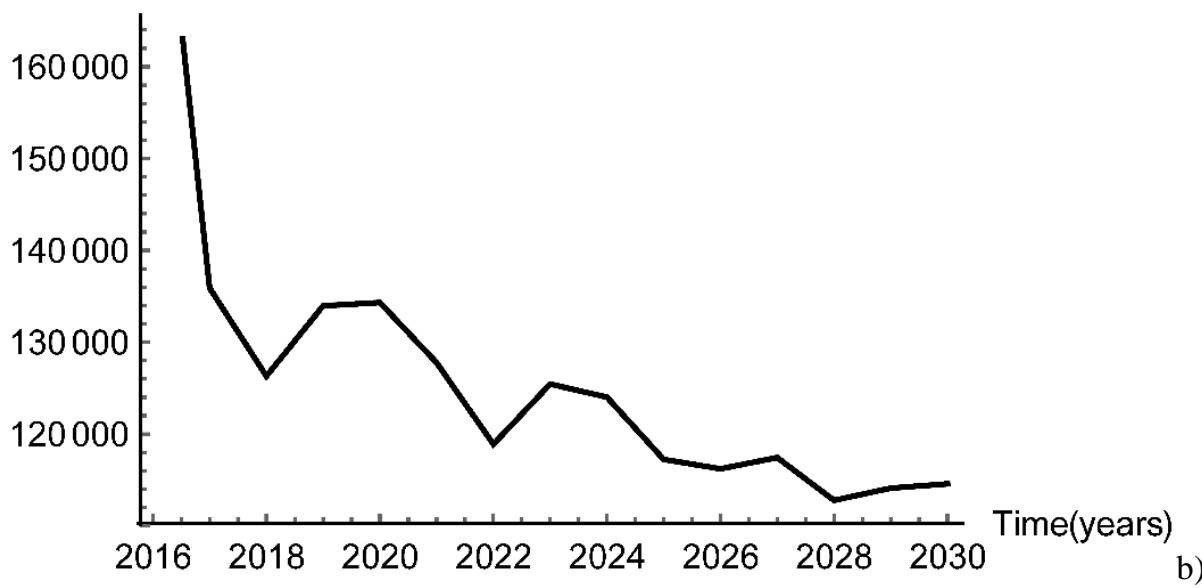

Male Immigration[people]

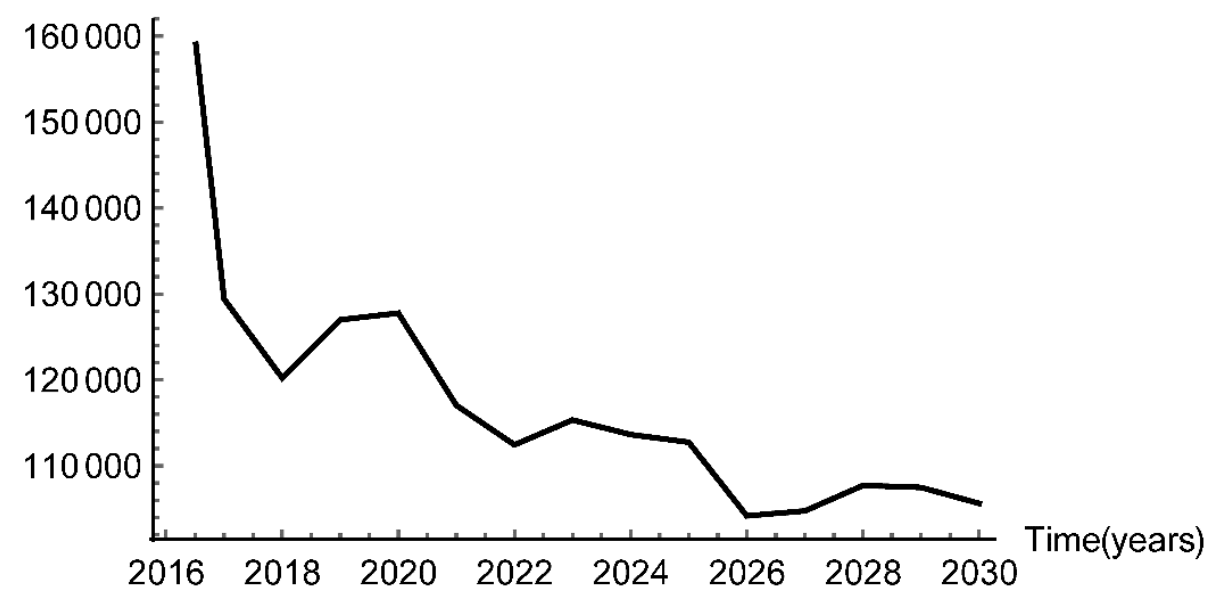

Fig. 10. Extrapolation of Immigration: a) female, b) male, in Spain in the 2016-2030 period for Strategy 1 and Scenario 1.

Table A.1

Variables used in the model

\begin{tabular}{|c|c|c|c|}
\hline Variable & Definition & Variable & Definition \\
\hline CRPO & Percentatge of Crimes and violence & RFER2 & Male Fertility Rate \\
\hline DEIN & Development Index & RINM1 & Female Immigration Rate \\
\hline EDIF & Female Education Index & RINM2 & Male Immigration Rate \\
\hline EDIM & Male Education Index & $R I P R$ & At-risk-of-poverty rate \\
\hline EDIN & Educacion Index & RPTS & Pupil-teacher ratio, primary school \\
\hline EDLI & Education Quality & SOIN & Solidarity Index \\
\hline EQUI & Environmental Equality Index & $X A D R$ & Material Deprivation rate \\
\hline EXIM & Exports and imports & $X E B F$ & Female life expectancy at birth \\
\hline EYSC & Expected years of schooling & XEBI & Life expectancy at birth \\
\hline FRIN & Freedom Index & $X E B M$ & Male life expectancy at birth \\
\hline GNIP & Gross National Income per capita (PPP \$) & ХITO & International inbound tourists \\
\hline HAIN & Happiness Index & XNST & Stock of immigrants \\
\hline JUIN & Justice Index & $X P S U$ & Mobile phone subscriptions/Internet Users \\
\hline PEIN & Peaceful Index & $X Y S C$ & Mean year of schooling \\
\hline PEMA & $\begin{array}{l}\text { Performance of } 15 \text {-year-old students in } \\
\text { mathematics (PEMA) } \\
\text { Performance of } 15 \text {-year-old students in }\end{array}$ & YCRP & Crimes and violence Index \\
\hline PERE & $\begin{array}{l}\text { Performance of } 15 \text {-year-old students in } \\
\text { reading (PERE) }\end{array}$ & YEXI & International Trade Index \\
\hline
\end{tabular}




\begin{tabular}{|c|c|c|c|}
\hline PESC & $\begin{array}{l}\text { Performance of } 15 \text {-year-old students in } \\
\text { science (PESC) }\end{array}$ & YEYS & Expected years of schooling Index \\
\hline PEXE & $\begin{array}{l}\text { Public expenditure on education } \\
\text { Share of total population living in a }\end{array}$ & $Y G N I$ & Gross National Income per capita Index \\
\hline$P L D W$ & dwelling & YIIT & International inbound tourists Index \\
\hline POOF & Police Officers & YINS & Stock of immigrants Index \\
\hline$P O P F$ & Female Population & $Y M A D$ & Material Deprivation Index \\
\hline$P O P M$ & Male Population & $Y M P S$ & Internet Users Index \\
\hline$P O P T$ & Total Population & $Y M S C$ & Mean year of schooling Index \\
\hline PRJU & $\begin{array}{l}\text { Professional Judges } \\
\text { Performance of 15-year-old students in } \\
\text { reading (PERE), mathematics (PEMA) }\end{array}$ & YPEM & Index Maths \\
\hline PRMS & and science (PESC) & $Y P E R$ & Read Index \\
\hline$P R P F$ & Proportion of female population & YPES & Science Index \\
\hline$P R P M$ & Proportion of male population & $Y P E X$ & Public expenditure on education Index \\
\hline PRPO & Prision Population & $Y P L D$ & Share of total population Index \\
\hline PSTT & Primary school teachers trained to teach & YPOO & Police Officers Index \\
\hline RAHO & Homicide rate & $Y P R J$ & Professional Judges Index \\
\hline RAMI & Net migration rate & $Y P R P$ & Prison population Index \\
\hline$R D E F 1$ & Female Mortality Rate & $Y R A H$ & Homicide rate Index \\
\hline$R D E F 2$ & Male Mortality Rate & $Y R E D$ & Research and development expenditure Index \\
\hline$R E D E$ & Research and development expenditure & YRI2 & Prison Index 2 \\
\hline REMM1 & Female Emigration Rate & YRIP & At-risk-of-poverty Index \\
\hline REMM2 & Male Emigration Rate & $Y R P T$ & Pupil-teacher ratio Index \\
\hline RFERI & Female Fertility Rate & & \\
\hline
\end{tabular}

\section{List of equations of the model:}

XYSC XYSC $=10.80443252902097+0.00009184150276909391 /(1-1.0000440026272446 * \mathrm{Exp}(-$ $0.000004294818477165572 *(2004-($ temi+1))))

EYSC

eysc $=11.748543187247233+4.204856880905447 /(1+4.204856880905447 * \operatorname{Exp}(0.21985311$ $174977828 *(1981-$

$($ temi+1)) ) ) +1.827744623273884/(1+112.79244564482674*Exp (0.7937658292237788*(2 $004-($ temi+1))) )

GNIP

gnip $=(1.1482983617421205+3.5833641448182862 /(1+12.574050955826271 * \mathrm{Exp}(0.17357$

$529868501334 *(1991-($ temi+1)) )) -

$0.6966116553589028 /(1+0.02152705086452519 * \operatorname{Exp}(1.1994101939350235 *(2013-$

$($ temi+1))))) *10000

RPTS

rpts $=29.116655484915594-$

$16.691517771110192 /(1+146.48738852171417 * \operatorname{Exp}(0.2347200065749017 *(1971-$

$($ temi+1))))

PEXE

pexe $=1.8363341070146955+2.5808465621528622 /(1+90.81562214139826 * E \times p(0.2755194$ $317136438 *(1970-($ temi +1$))))$

XITO xito $=(-1006.79-3.00872 \mathrm{e} 6 /(1-1990.37 * \mathrm{Exp}(-0.0500777 *(2001-$ $(\operatorname{temi}+1))))+921.365 /(1+4.29389 * \operatorname{Exp}(0.406178 *(2003-(\operatorname{temi}+1))))) * 100000$ XPSU

$\operatorname{xpsu}=17.950334198545377+83 /(1+1.1776687271504054 * \operatorname{Exp}(0.14136810893333482 *(200$ $7-($ temi+1))) ) 


\section{EXIM}

exim $=(0.5844424305513581+0.20459280113771572 /(1+110.98404835345215 * \operatorname{Exp}(1.1626$ $769130755628 *(1991-($ temi 1$))))-0.16324885771874656 /(1+(1.625972507547136 e-$

$10) * \operatorname{Exp}(23.53299367865115 *(1994-(t e m i+1))))) * 100$

$\mathrm{REDE}$

rede $=0.44579656485181224+1.6457913420400998 /(1+0.38967265534324685 * \operatorname{Exp}(0.4743$ $26895896085 *(2008-($ temi+1) $))$

$0.9102250392552589 /(1+1.1776064552846774 * \operatorname{Exp}(0.48014303403960146 *(2009-$ $($ temi+1))) )

PRPO prpo $=140.3115870321866+23.22658496403643 /(1+0.06864390632532874 * E \times p(-$ $1.3009707490844389 *(2009-($ temi+1))))

RIPR ripr $=-2496.213388206712+5179.099775224933 /(1+(3.411904592754598 \mathrm{e}-7)$ *Exp $(-$ $0.8663579422441744 *(1995-$

$($ temi +1$))))+19192.704080563683 /(1+2.52682798448037 * \operatorname{Exp}(0.15044967128370496 *(2$ $008-(t e m i+1)))$ )

XADR xadr=-141353. - 21145.1/( $1-1.14959 * \operatorname{Exp}((-1.34654 \mathrm{e}-6) *(2004-$ $($ temi+1))) $)+27.1722 /(1+1.37298 * \operatorname{Exp}(0.302733 *(2010-(\operatorname{temi}+1))))$

PRJU prju=12.215421162434668-2.7892442364225785/(1+0.10504122972808097*Exp($0.55406560371907 *(2008-($ temi +1$))))$

$\mathrm{CRPO}$

$\mathrm{Crpo}=(1.2768598905888036+1.1938767310484462 /(1+4.724589254926666 * \mathrm{Exp}(0.209570$

$73591854128 *(1991-($ temi 1$))))) * 1000000$

YEVM yevm= (evmu-22.5)/(87.5-22.5)

YEVH yevh $=($ evho-17.5) / (82.5-17.5)

YEVD yevd=1/( (prpm/yevm) $+(\mathrm{prpv} /$ yevh $))$

YMSC ymsC $=\left(x_{y s C}-0\right) /(15-0)$

YEYS yeys $=($ eysc -0$) /(18-0)$

EDIN edin $=($ ymsctyeys $) / 2$

YGNI ygni $=(\log (g n i p)-\log (100)) /(\log (75000)-\log (100))$

PSTT pstt $=1$

YPEM ypem $=($ pema-100) $/(1000-100)$

YPER yper $=($ pere-100)/(1000-100)

YPES ypes $=($ pesc -100$) /(1000-100)$

PRMS prms $=($ ypem+yper + ypes $) / 3$

YRPT yrpt $=($ rpts -7$) /(25-7)$

YPEX ypex $=($ pexe-2) $/(10-2)$

EDLI edli=(pstt*prms*ypex/yrpt)^(1/4)

DEIN dein $=(\text { yevd*edin*ygni*edli })^{\wedge}(1 / 4)$

RAMI rami $=1$

XNST xnst $=$ emi $i * 100 /$ pobi

YINS yins $=($ xnst -0$) /(100-0)$

YIIT yiit $=($ xito-0) $/(100000000-0)$

YMPS ymps $=(x p s u-0) /(100-0)$

YEXI yexi $=($ exim-0) $/(100-0)$

YRED yred $=($ rede-0) $/(5-0)$

FRIN frin $=(\text { rami*yins*yiit*ymps*yexi*yred })^{\wedge}(1 / 6)$

YCRP ycrp $=$ crpo/pobi

YRAH yrah=raho/10

PEIN pein=1-(ycrp*yrah $)^{\wedge}(1 / 2)$

YRIP yrip $=($ ripr $\star 100) /($ pobi $)$

YPLD ypld $=(\mathrm{pldw} / 100)$

YMAD ymad $=x a d r / 100$

SOIN soin=((1-yrip)* $(1-y p l d) *(1-y m a d)) \wedge(1 / 3)$

YPOO ypoo=poof/pobi

YPRJ yprj=prju/pobi

XUIN xuin $=((1-\text { ypoo }) *(1-\text { yprj }))^{\wedge}(1 / 2)$

FELT felt $=(\text { dein*frin*xuin*pein*soin })^{\wedge}(1 / 5)$ 


\section{References}

[1] https://www.collinsdictionary.com/es/ (accessed 15.01.2018).

[2] N. Extremer, P. Fernández-Berrocal, The Subjective Happiness Scale: Translation and preliminary psychometric evaluation of a Spanish version, Soc. Indicators Res. 119(1) (2014) 473-81.

[3] https://www.iim-edu.org/thinktank/papers/gnw-index/index.htm (accessed 15.01.2018).

[4] E. Diener, R.A. Emmons, R.J. Larsen, S. Griffin, The Satisfaction with Life Scale, J. Pers. Assess. 49 (1985) 71-75.

[5] S. Lyubomirsky, H. Lepper, A Measure of Subjective Happiness: Preliminary Reliability and Construct Validation, SOCI 46 (1999) 137-155.

[6] C. Graham and A. Felton, Inequality and Happiness: Insights from Latin America, J. of Economic Inequality, Vol. 4 (2006), 107-122.

[7] B.S. Frey, Happiness. A Revolution in Economics, 2008. MIT Press.

[8] A. Deaton, The financial crisis and the well-being of Americans, Oxford Economic Papers, 64 (2013), $1-26$.

[9] http://happyplanetindex.org (accessed 15.01.2018).

[10] http://www.grossnationalhappiness.com/ (accessed 15.01.2018).

[11] UNDP, Human Development Report 2014. Oxford University Press. New York, Oxford, 2014.

[12] A. Caselles, Trying to evaluate human dignity in a social group, Adv. Syst. Sci. Appl. 15(1) (2015) $72-89$.

[13] M.T. Sanz, A. Caselles, J.C. Micó, D. Soler, Including an environmental quality index in a demographic model, Int. J. Glob. Warm. 9(3) (2016) 362-396.

[14] http://ec.europa.eu/eurostat (accessed 15.01.2018).

[15] M.T. Sanz, J.C. Micó, A. Caselles, D. Soler, A stochastic model for population and well-being dynamics, J. Math. Sociol. 38 (2) (2014) 75-94.

[16] D. Soler, M.T. Sanz, A. Caselles, J.C. Micó, A stochastic dynamic model to evaluate the influence of economy and well-being on unemployment control, J. Comput. Appl. Math. 330 (2018) 1063-1080.

[17] H. Marques, G. Pino, J.D. Tena (2013) Do happiness indexes truly reveal happiness? Measuring happiness using revealed preferences from migration flows. (http://hdl.handle.net/10016/16793, accessed 15.01.2018)

[18] G. Felbermayr, F. Toubal. Revisiting the Trade-Migration Nexus: Evidence from New OECD Data, World Dev. 40(5) (2012) 928-937.

[19] G. Hanson, C. McIntosh. Birth rates and border crossings: latinamerican migration to the US, Canada, Spain and the UK. Econ. J. (London), 122 (2012), 707-726.

[20] M. Rojas. Economía de la Felicidad: Hallazgos relevantes respecto al ingreso y el bienestar, Trimest. Econ. 76 (303) (2009) 537-573.

[21] G. Oxa, V. Alcides, C. Arancibia, S. Campero. Economía de la Felicidad: evidencia empírica para Latinoamérica, Perspectivas (34) (2014) 159-180.

[22] A. Aparicio, Bienestar subjetivo del consumidor y concepto de felicidad, Argumentos 24 (67) (2011) 67-91.

[23] http://databank.worldbank.org/data/home.aspx (accessed 15.01.2018).

[24] UNDP, Human Development Report. New York: Oxford University Press, 2010.

[25] https://www.cato.org/human-freedom-index (accessed 15.01.2018).

[26] http://www.humanrightsdata.com/ (accessed 15.01.2018).

[27] https://infographics.economist.com/2017/DemocracyIndex/ (accessed 15.01.2018).

[28] http://www.heritage.org/index/ (accessed 15.01.2018).

[29] J.C. Micó, A. Caselles, D. Soler, Age-Structured Human Population Dynamics, J. Math. Sociol. 30 (2006) 1-31.

[30] A. Caselles, D. Soler, M.T. Sanz, J.C. Micó, Simulating Demography and Human Development Dynamics, Cybernet. Syst. 45 (6) (2014) 465-485.

[31] J. W. Forrester, Industrial dynamics. Cambridge: MIT Press, 1961.

[32] Caselles, A. (1998). A tool for discovery by complex function fitting. In Cybernetics and Systems Research'98. R. Trappl (ed.). Austrian Society for Cybernetic Studies. Vienna. pp. 787-792. 
[33] Caselles, A. (2008) Modelización y simulación de sistemas complejos (Modeling and simulation of complex systems). Universitat de València. Valencia (Spain). (Available in http://www.uv.es/caselles as well as SIGEM, accessed 15.01.2018)

[34] K. Djidjeli, W.G. Price, P. Temarel, E.H. Twizell, Partially implicit schemes for the numerical solutions of some non-linear differential equations, Appl. Math. Comput. 96 (1998) 177-207.

[35] C. Letellier, S. Elaydi, L.A. Aguirre, A. Alaoui, Difference equations versus differential equations, a possible equivalence for the Rossler system? Phys. D: N.a. Phenom. 195 (2004) 29-49.

[36] http://www.wolfram.com/mathematica/ (accessed 15.01.2018). 